REST Journal on Emerging trends in Modelling and Manufacturing
Vol: 7(3), 2021
REST Publisher
ISSN: 2455-4537

\title{
A Review on Various Implications on Re engineering in Manufacturing
}

\author{
Dr. Amol Lokhande, Dr. C. Venkateswaran, Dr. M. Ramachandran, S. Chinnasami, T. Vennila \\ School of Engineering and Technology, Sandip University. Maharashtra, India. \\ Management Studies department, Maharishi Markandeshwar (Deemed to be University), Ambala, Haryana. India. \\ REST LABS, Kaveripattinam, Krishnagiri, Tamil Nadu, India. \\ Email: venky.professor@gmail.com
}

\begin{abstract}
Re-engineering is a software development process that is done maintenance. Re-engineering is experiment and transformation of a system into a new form. This process involves a ancillary and reconstruction, both of which refer to further investigation or engineering of the finished product, and the methods of doing so and the desired results are very different. Reverse engineering focuses on the analysis and design of workflow and business processes within an organization in the early 1990s, trying to figure out how it works. BPR aims to help companies reconsider reduce operating Functional efficiency. These processes are characterized by several properties.
\end{abstract}

\section{Introduction}

Research has suggested that there are deficiencies in critical skills.Regenerating "A trade war cry was first heard in the early 1990s, citing the publication of the 1993 book by most commentators and consultants Michael Hammer and James Champ. People have traditionally called it "restoration," but, at its beginning, "from the beginning", "blank slate," and "came from the bottom with a specific taste. "Its promoters have argued radical approaches, functional reengineering is doing what a business seeks to reconsider its objectives but how it is done to change the corporate culture. E slim, fast, effective, responsive, competitive, agile and focused. Etc.) Since it can be applied to corporations as a whole or as a specific process, it is called business process restructuring and abbreviated PPR.Re-engineering came at a time when the waves of many management techniques were already colliding on the rocky shores of the corporate bureaucracy and thus, it was immediately branded as a fad but zero. Based on the budget (another-floor approach), its predecessors and competitors in concepts or techniques such as intra prenatal, vision, de-machining, de-layering. Functional practices embedded in the restructuring system or in its operation Total Quality Management (TQM), continuous improvement and concept of Toyota-led "Lean Corporation" include timely delivery, effective operational clustering, and cross-training of staff. This is sometimes related to the Gig-popularized quality control objective invented by Six Sigma, Motorola.

\section{Re engineering}

The re-engineering experiment and transformation of a system into a new form. This process involves ancillary forward engineering, and reconstruction. In HR performance. There are four key words in this definition: "review" - which refers to the total review. Many of the Does not match Existing tools or substantial are commonly efforts Computer Dynamics and Symmetric Score Card (BSc). However, there are limits to restrict the adoption by practitioners of the already mentioned intrinsic problems of computer dynamics. This is evident in manufacturing companies, whereas unique event simulation is a tool used to improve productivity, but it does not solve quality process control problems. Focusing on improving individual components or processes rather than $\mathrm{E}$, Godard reiterates what has been known in computer dynamics for three decades, that although the performance of each process in an organization is individually optimal, the overall system performance is not optimal. $\mathrm{T}$ is powered by software from the cloud. Enterprise software "from the cloud" is comparable to other business services. It goes hand in hand with According to the precedent Re-engineering enterprise software is powered by software "from the cloud" is comparable to other business services. It goes hand in hand with re-engineering enterprise software according to the paradigm. The same thing is happening in World of Services. Services re-engineering creates a world highly basic types required in the Sass landscape are already known. The term "reverse engineering" Existing tools or substantial programming and software engineering skills are commonly found in most companies. Nain security Situation Reverse engineering forum where Software maintenance and development communities meet, and various terms for technologies to analyze and understand existing systems are often misused or used in conflicting ways. Employees need to restructuring methods, review the reward mechanism,move the restructured company forward, and promote the desire to share information, and to use experience in redesigning Redesign processes from large-scale changes to organizational structures. Management systems and values, therefore managers must carefully target important (crossfunctional) business processes; (2) managers need to adjust organizational practices that focus on meeting internal 
Demands rather than market; and (3) focus on results rather than task. Other factors proposed: (1) Technology is seen as a process, not a solution The first of the two is the most common But the need for change. Changes involve both function and execution technique. The change of function is to remove two limitations of the current system. It only allows one address per customer and one user can only work through an invoice at that time. When large methods are handled, each restructuring action will have a greater impact based on the size of the source code involved. But this is not the only reason to consider large-scale methods of restructuring. Therefore, combining with long is highly beneficial for reducing the probability of errors. This section presents a set of properties that reflect some of the most influential aspects of the restructuring. Quote from management authority Peter Trucker, who adorns the cover of the best-selling book about restructuring (Hammer and Zambi, "Restructuring is New!" , Organizational changes, including. There is currently no clear agreement among researchers as to whether animation visualization is effective, although a significant number of people believe it. Also, the difference of belief and the actual use of the animated visualization is interesting. This difference illustrates part of the uncertainty about animated visualization. Only a few researchers have animation visualization experiences, and as a result, more case studies and experiments should be conducted before more research is invested in specific animation techniques. We need to identify domains where animation can actually help. Visualization of dynamic features was proposed by several respondents

\section{Customer Satisfaction}

Regular (not occasional). Proper accreditation may include weekly, monthly, and quarterly. Annual Awards-Complaint Reduction. Number of nominations. And so on. Although the award criteria are measurable, 115 it is not always straightforward to compare the measured results of one group with another. Some judgments - the awards committee may still enter. Every year, Motorola brings together 20 odd teams (delivered from around 3,000 people worldwide) to a top Chicago area hotel for its "Total Customer Satisfaction Team Competition". Using statistics, scatter and fish bone maps and humor, the teams present their plans and manage the best management score tables. In the first phase of the period, the company conducted business as usual; In the second phase, the company began implementing a process restructuring initiative. The restructuring plan caused some changes in the content of specific jobs. In addition, the duration of this transition may result in increased levels of experienced stress and demands [38] This may require considerable effort if the pressure is on fast system delivery due to the nature of the PPR plans. Maintaining ES Development Team relationships with long-term collaborative IS department or end user sector managers. Employees have the opportunity to promote employee satisfaction in specific projects. Methods generally focus on cross-functional and integrated processes. They take customer perspective and use ID's integration and processing capabilities. Methods that empower individuals and groups and measure performance gains are related to customer satisfaction and profitability. In summary, the S-A framework of the BPR Plan illustrates the essence of the BPR Plan as a set of concerted efforts to transform various organizational affiliates through business process change. In an active environment, a company's ability to open up to the public Crucial to its success. Processes, can be advanced technology and strategy quickly copied and pasted by People. Managing knowledge capital is the key to success with little understanding. Acquiring, cultivating, Retaining and moving the capital of knowledge to "moments of reality "Customer Contact Points Due to retain customer orders (confirmed and anticipated) in the 1990s. Implementing TQM brought 98 percent improvement in meeting specific dates. Before TQM was used as an integrated production mechanism, Bournemouth jobs met only 40 percent of its distribution obligations.

\section{Supply Chain Management}

The supply chain network is a network of autonomous or semi-autonomous business entities engaged in various processes and processes through overhead and down line connections common distribution chain network, with terminals representing businesses connected by connections. An SCN can be viewed from different angles: a processing strategy works for this purpose to meet the requirements for customized products; however, extending reduces. Organizational participants do not agree on the nature of the problem to be solved once; (2) There is uncertainty as to sites involved are in very valuable and short distribution. Many donation studies oppose institutional strategies and methods and suggest the possibility of tragedy in such a political game. Repressions' deleting releasing the bond, stimuli, there is a DTA (dead-off) or "reverse" DTA (RTDA) or "reverse" DTA (RTDA) exposure driving driver in which 4-point mutations were made to keep the DG expression quiet. From Teaks, Dig. Apparently, D.G. Exposure only works in the presence of drugs. However, this is a provisional explanation, however, as members are not asked to provide reasons behind the OIQ's preferences. Nevertheless the possibilities of this interpretation suggest that inquiries into multiple identities (and related knowledge) should be the second major contribution of the study to the Identity Scholarship when trying to understand the cast of the exams focusing on the identity duality (or "identity replacement") discussed by Scott et al. It was researched in a study of a contradiction in a conflict of a symphony orchestra that was skillfully explored in a clash in a symphony orchestra, and the target of the artist's independent claims made by the composers was that the claims of each page were similar to the claims of each page wanting to shape the identity of the whole segment. In the DBC case, a Most DBC members including a majority of Members of other working groups rejected DOS and PC requests for a joint change. Section 2 introduces the Operation Execution Process (OFP), which illustrates the need to integrate supply chain networks (SCNs) in Section 2. Section 5 is devoted to describing various development strategies. A Diversity Information System Approach and Proposed Strategies across assessments. We make short decisions. Automated-ID-enabled Product Data 
Collection System Production data collection emerged during the Integrated Production (CIM) period. In recent years, RFID has grown into an important auto-IT technology that has many special advantages over others, such as barcodes, including longer reading distances, larger data storage and more. A broader approach has been depicted to capture repair work data on a car production line using RFID technology. The help of EISS above, Kedah has developed change to customer order change. Management and Personality inked the UK Government basically applies the new, efficient and civic and business to various parts of government, citizens and businesses. The Government of the United Kingdom has set an ambitious goal of implementing 1 is located has a vast population of 221,600 covering a wide range of cultures and nationalities. Contains a set of services D, cultural change organization also held throughout the organization. According to CSM, now people are more responsible for their work and motivated and front line people work' attitude; A decision was made to focus on review in the "research literature". For the purpose of this paper, there are articles in periodical literature research literature. Often popular (lean) management books are added due to in the development of the fields. Even documents of the conference assessment, lean construction seemed important for discussion, discussing slim production and slim production as providing, examining the in slim. The study acknowledges that the activities promoted under the Cinema Production / Production (or Toyota Production System) label will be favorable by understanding the implications of active production / production, depending on the circumstances. According to Souza Montero and Co swell (2008), retailers are the driving force behind the introduction of quality assurance and the Traceability system across the leadership supply chain. Vendors can impose stricter standards than are mandatory. For example, Eurepgap was formed by a group of leading Northern European retailers who joined forces with the Euro-retailer Working Group (Eurep).

\section{Business Process Re-Engineering}

Project Review Traditional measurement systems may have two nodes sword for operational managers. More and more companies are using a consistent scorecard of performance to identify and communicate key factors that promote better indicators demand and future value. It is capable. Within the above definition are important theories of approach. First, the radical and progressive standard increasing. PPR classified overall, manual specifically for consider or engage restructuring. The main contribution of the book is to provide a comprehensive and comprehensive set of instructions that are not found in many "restoration" books. The motivation for restructuring is usually the result of a change, which should be acted upon by a senior manager or "sponsor". Motivation may be the loss of market share, fear of aggressive competitors or the goal of expanding the stock or entering new markets. Restructuring is defined here as "the radical and rapid redesign of strategic, value-added business processes - and the systems, political and organizational structures that support them - improving workflows and productivity within an organization." This section contains a case study that presents and discusses the results of an employer study related to engineering graduates. In line with previous research previously described, the Manish University 2007 employer survey found a lack of alignment between engineering graduate characteristics and employer requirements. Possible solutions to the lack of alignment are also proposed in this case study. These staffs initially contacted potential survey participants by phone to explain the purpose of the study, request organization participation, and identify the best qualified person to complete the survey. Communication with that person was then initiated and arrangements made for a more convenient management system (telephone, paper based or online completion). The first restructuring attempt It took place in the United Kingdom (UK), where a major regulatory change called for redefining the unit's business strategy. The six-month analytical review assessed the impact of the new strategy on business organization, operations and cost drivers. Nearly 40 percent of the business was abandoned. The operational unit (i.e., customer service, financial accounting, claims) was moved from the suburbs of London to the new, low-cost location of Greenock, Scotland. Marketing, Sales and Underwriting redevelopment in London ensured that new behaviors in financial measurements, billing and commissions would be rewarded. The information systems system was similarly changed. The 57-member team was reduced to 22 people, and to re-energize its responsible area restructuring effort, the CIO and his management team brought in a new CIGNA restructuring director from an outside consultation. They wanted to move away from so-called "first wave" of restructuring efforts that focused primarily on cost reduction and improving service delivery. External consulting firm to assess whether they have the skills and competencies required for the position. The study results are significant implications for MIS specialists. Our findings suggest that technical skill is essential but not enough to succeed again. To succeed in restructuring, it is important to master change management that demands sophisticated people and business skills. MIS professionals who are accustomed to "structured" projects aimed at the automation of existing procedures may need to restructure and additional training for the "unconstructed" project environment in the restructuring. The problem list and sections are based on the research literature concentrated on functional theories and experience from the field. A large number of restructuring plans have been included in the model to generate results with some generalization. The advantage is called restructuring which originally made radical improvements in Hammer (Davenport and Short. In their quarterly reports, they report on slow restructure the failure rate is low. Ations integrated into management processes.CSFs of the system. Although the selection criteria may vary by system, an approach to "assigning a value of" E "and a value of 1." Once a process has been documented, identifying problems and rootcases (S3A2) is a precursor to redesigning. Used to assess pathology and determine which areas should be improved.s5A1). The results of the study indicate that the $\mathrm{ABC}$ technique is integrated into several integrated BPR instruments. Research integrity is strengthened by the integration of statistical analysis of case-based quality research and quantitative data. Quality research for the results reported in this study is based on the case studies of four leading companies who were the early adopters of the CFW. . The telephone survey of retailers provided additional quality 
information. Davenport et al. They argue that PPR should take a comprehensive look at ID and business activities and the relationships between them. ID skills should support business processes, and business processes should be based on the capabilities that ID can provide. They believe that the promise of information technology and its ultimate impact will be a very powerful tool to reduce integration costs.

\section{Manufacturing}

The uniqueness of ERP systems became even clearer when SAP AG, also known as RAP, released its next-generation software. The release of R / 3 marked the transition from the mainframe to technologically advanced platforms to the increasingly popular Unix-based client-server architecture. In the following years, manufacturing and some service companies joined SAP and its main competitors Oracle, Pan, Peoplesoft and JT. Since activities related to planning and installing ERPs are generally more expensive than software products, consultants and systems coordinators are actively moving into the implementation market. The current market price of a third-party product is approximately 3,55 (e / unit) (total annual outsourcing cost e852.000). Therefore, net savings is 0.19 (e / unit)may re-encourage this production process. Izatiooalgoodun included in ENREMOS is a graC :. Search process without derivatives. model creates the selfconfiguration of its control.The bell-shaped function. Previously introduced. Finally these seJf-companies must move the current stored balance of the fitted reference model to the desired equilibrium by the target market of the analyzed production system. Creating an IDEF model is only one component of a comprehensive process modeling effort. Representing IDEF models as process diagrams, observation model analysis and IDEF model structure analysis are the issues discussed in this paper. The basics of IDEF0 and IDEF3 are discussed, however, the importance of paper lies in the design and production processes of model analysis and reconstruction. Extended a triangulation algorithm from Kuziak et al. [11] Process is provided for sample analysis. IDEF0 introduced technologies. Two of these are manufacturing companies in the Southeast and the third is a state government in the Southeast. The other organization is a Midwest-based consulting firm that specializes in business restructuring. Participants in the interview were given an initial version of the categorized problem list and the problems were added, removed or changed during the interview. Based on these domain interviews, personal implementation issues were modified and new issues were added based on their experience. We distinguish companies that create electronic market adoption consumers from consumer electronics shopping systems on the Internet. The immense growth of the Internet and especially the World Wide Web has increased the number of new intermediaries such as the Internet Store, Internet Mall, Industrinet and the Internet Shopping Network. Utilize the new type of economics, scope and knowledge implemented through the Internet [31]. These intermediaries allow sellers to advertise their products to millions of prospective consumers, while at the same time allowing customers to order

\section{Conclusion}

The adoption by practitioners of the already mentioned intrinsic problems of computer dynamics previously introduced. Finally Companies are moving the balance. Consultants and computer coordinators are also actively moving in the implementation market. Maps are techniques that allow restructuring teams to assign process measures to cost centers and measure process performance (S5A1). Quantity is important in customizing the S-A method There is a lot of discussion within the literature on what are the right costs for operational restructuring and restructuring into organizations. The first restructuring attempt called for redefining. Will be announced, were required to apply for these positions. Each manager Interviewed by an outsider Consulting firm to evaluate whether they have the skills and competencies required for the position. Restructuring is defined here as "radical and rapid redesign of strategic, value-added business processes — and the systems, political and organizational structures that support them - improving workflows and productivity in an organization." However, in the case of DBC, most DBC members - including most Members of other working groups rejected DAs and PCs' demands for joint change.

\section{References}

1. Barber, Kevin D., Frank W. Dewhurst, R. L. D. H. Burns, and J. B. B. Rogers. "Business- process modelling and simulation for manufacturing management: A practical way forward." Business Process Management Journal (2003).

2. Chan, K. K., and Trevor A. Spedding. "An integrated multidimensional process improvement methodology for manufacturing systems." Computers \& Industrial Engineering 44, no. 4 (2003): 673-693.

3. Wortmann, Johan C., Hans Don, Jan Hasselman, and Alex Wilbrink. "Enterprise information systems as a service: re-engineering enterprise software as product-service system." In IFIP International Conference on Advances in Production Management Systems, pp. 496-505. Springer, Berlin, Heidelberg, 2011.

4. Chikofsky, Elliot J., and James H. Cross. "Reverse engineering and design recovery: A taxonomy." IEEE software 7, no. 1 (1990): 13-17.

5. Guimaraes, Tor, and Ketan Paranjape. "Testing success factors for manufacturing BPR project phases." The International Journal of Advanced Manufacturing Technology 68, no. 9-12 (2013): 1937-1947. 
6. Jacobson, Ivar, and Fredrik Lindström. "Reengineering of old systems to an object-oriented architecture." In Conference proceedings on Object-oriented programming systems, languages, and applications, pp. 340-350. 1991.

7. Bhatnagar, Rohit, and S. Viswanathan. "Re- engineering global supply chains: alliances between manufacturing firms and global logistics services providers." International Journal of Physical Distribution \& Logistics Management (2000)

8. Balazinska, Magdalena, Ettore Merlo, Michel Dagenais, Bruno Lague, and Kostas Kontogiannis. "Measuring clone based reengineering opportunities." In Proceedings Sixth International Software Metrics Symposium (Cat. No. PRO0403), pp. 292-303. IEEE, 1999.

9. Davenport, Thomas H., and Donna B. Stoddard. "Reengineering: business change of mythic proportions?." MIS quarterly (1994): 121-127.

10. Schonberger, Richard J. "Human resource management lessons from a decade of total quality management and reengineering." California Management Review 36, no. 4 (1994): 109-123.

11. Burke, Ronald J., Jim Graham, and Frank Smith. "Effects of reengineering on the employee satisfaction- customer satisfaction relationship." The TQM Magazine (2005).

12. Yoon, Youngohc, Tor Guimaraes, and Aaron Clevenson. "Exploring expert system success factors for business process reengineering." Journal of Engineering and Technology Management 15, no. 2-3 (1998): 179-199.

13. Kettinger, William J., James TC Teng, and Subashish Guha. "Business process change: a study of methodologies, techniques, and tools." MIS quarterly (1997): 55-80.

14. Hormozi, Amir M. "Agile manufacturing: the next logical step." Benchmarking: An international journal (2001).

15. Nwabueze, Uche. "Process improvement: the case of a drugs manufacturing company." Business Process Management Journal (2012).

16. Lin, Fu-Ren, and Michael J. Shaw. "Reengineering the order fulfillment process in supply chain networks." International Journal of Flexible Manufacturing Systems 10, no. 3 (1998): 197-229.

17. Sanbe, Atsushi, James Gulick, Mark C. Hanks, Qiangrong Liang, Hanna Osinska, and Jeffrey Robbins. "Reengineering inducible cardiac-specific transgenesis with an attenuated myosin heavy chain promoter." Circulation research 92, no. 6 (2003): 609-616.

18. Legat, Christoph, Daniel Schütz, and Birgit Vogel-Heuser. "Automatic generation of field control strategies for supporting (re-) engineering of manufacturing systems." IFAC Proceedings Volumes 45, no. 6 (2012): 1574-1579.

19. Kambil, Ajit, and Eric Van Heck. "Reengineering the Dutch flower auctions: A framework for analyzing exchange organizations." Information Systems Research 9, no. 1 (1998): 1-19.

20. Lin, Fu-Ren, and Michael J. Shaw. "Reengineering the order fulfillment process in supply chain networks." International Journal of Flexible Manufacturing Systems 10, no. 3 (1998): 197-229.

21. Zhong, Ray Y., Q. Y. Dai, Ting Qu, G. J. Hu, and George Q. Huang. "RFID-enabled real-time manufacturing execution system for mass-customization production." Robotics and Computer-Integrated Manufacturing 29, no. 2 (2013): 283-292.

22. Weerakkody, Vishanth, Marijn Janssen, and Yogesh K. Dwivedi. "Transformational change and business process reengineering (BPR): Lessons from the British and Dutch public sector." Government Information Quarterly 28, no. 3 (2011): 320-328.

23. Jørgensen, Bo, and Stephen Emmitt. "Lost in transition: the transfer of lean manufacturing to construction." Engineering, construction and architectural management (2008).

24. Kister, Joanna. "Life Planning Resource Guide. A Resource for Teaching the Life Planning Core Course Area of Ohio's Work and Family Life Program." (1994).

25. Lowe, Kevin B., and K. B. Lowe. "The Reengineering Handbook: A Step-by-Step Guide to Business Transformation." transformation 24, no. 1 (1995): 86-87.

26. Nair, Chenicheri Sid, Arun Patil, and PatricieMertova. "Re-engineering graduate skills-a case study." European journal of engineering education 34, no. 2 (2009): 131-139.

27. Caron, J. Raymond, Sirkka L. Jarvenpaa, and Donna B. Stoddard. "Business reengineering at CIGNA corporation: experiences and lessons learned from the first five years." Mis Quarterly (1994): 233-250.

28. Grover, Varun, Seung RyulJeong, William J. Kettinger, and James TC Teng. "The implementation of business process reengineering." Journal of management information systems 12, no. 1 (1995): 109-144.

29. O'Neill, Peter, and Amrik S. Sohal. "Business Process Reengineering A review of recent literature." Technovation 19, no. 9 (1999): 571-581.

30. Terziovski, Mile, Paul Fitzpatrick, and Peter O’Neill. "Successful predictors of business process reengineering (BPR) in financial services." International Journal of Production Economics 84, no. 1 (2003): 35-50.

31. Caputo, Antonio C., and Mario Palumbo. "Manufacturing re- insourcing in the textile industry: a case study." Industrial Management \& Data Systems (2005). 
32. Macedo, Julio. "Cognitive Maps for Reengineering the Organization of Manufacturing Systems." IFAC Proceedings Volumes 28, no. 24 (1995): 329-334.

33. Muscatello, Joseph R., Michael H. Small, and Injazz J. Chen. "Implementing enterprise resource planning (ERP) systems in small and midsize manufacturing firms." International Journal of Operations \& Production Management (2003).

34. Koschke, Rainer. "Software visualization in software maintenance, reverse engineering, and re- engineering: a research survey." Journal of Software Maintenance and Evolution: Research and Practice 15, no. 2 (2003): $87-$ 109.

35. Gerward, L., N. Guilbert, K. Bjørn Jensen, and H. Levring. "X-ray absorption in matter. Reengineering XCOM." Radiation Physics and Chemistry 60, no. 1-2 (2001): 23-24.

36. Bevilacqua, M., F. E. Ciarapica, and G. Giacchetta. "Business process reengineering of a supply chain and a traceability system: A case study." Journal of Food Engineering 93, no. 1 (2009): 13-22.

37. Attaran, Mohsen. "Exploring the relationship between information technology and business process reengineering." Information \& management 41, no. 5 (2004): 585-596.

38. Kusiak, Andrew, and T. Nick Larson. "Reengineering of design and manufacturing processes." Computers \& Industrial Engineering 26, no. 3 (1994): 521-536.

39. Grover, Varun, Seung RyulJeong, William J. Kettinger, and James TC Teng. "The implementation of business process reengineering." Journal of management information systems 12, no. 1 (1995): 109-144.

40. Lee, Ho Geun, and Theodore H. Clark. "Market process reengineering through electronic market systems: opportunities and challenges." Journal of Management Information Systems 13, no. 3 (1996): 113-136.

41. Lokhande, Amol D., R. L. Shrivastava, and Rashmi R. Shrivastava. "A REVIEW ON CRITICAL SUCCESS FACTORS OF RE-MANUFACTURING." International Journal of Entrepreneurship \& Business Environment Perspectives 3, no. 2 (2014): 982.

42. Kamble, A. G., R. Venkata Rao, A. S. Potdar, and A. D. Lokhande. "Prediction and optimization of spur gear pair by response surface method." Joumal on Advances in Science and Engineering, Section B 1 (2010): 23-28.

43. Dr. Amol Lokhande, Dr. C. Venkateswaran, Dr. M. Ramachandran, C. Vidhya, R. Kurinjimalar, A Study on Various Implications on Reusing in Manufacturing, REST Journal on Emerging trends in Modelling and Manufacturing 7(2) 2021, 63-69. 